\title{
Bohn's nodules: peculiar neonatal intraoral lesions mistaken for natal teeth
}

\author{
Mehmet Nevzat Cizmeci • Mehmet Kenan Kanburoglu • \\ Semra Kara • Mustafa Mansur Tatli
}

Received: 3 September 2013 / Accepted: 1 October 2013 /Published online: 17 October 2013

(C) Springer-Verlag Berlin Heidelberg 2013

\begin{abstract}
Inclusion cysts of transient nature during the neonatal period are developmental lesions, which are seen in the oral cavity of the newborn infant. These lesions are classified into three subtypes according to their localizations. When noticed by the anxious parents on the gingival surfaces, they are often mistaken for natal teeth, which lead to seeking medical attention. Herein, we describe a newborn infant with Bohn's nodules to increase the awareness of the physicians to this benign, self-limiting lesion.
\end{abstract}

Keywords Intraoral lesions $\cdot$ Newborn

A 7-day-old, 3,550-g male infant who was born at 40 weeks gestational age was brought to the neonatology outpatient clinic due to two small, white-colored, round-shaped protuberances on the maxillary gingival surface, which were assumed to be dental edges by the caregivers (Fig. 1). The lesion was firm and not tender to palpation. There was no erythema around it, and the physical examination was otherwise unremarkable.

Inclusion cysts of transient nature during the neonatal period are developmental lesions, which are seen in the oral cavity of the newborn infant. These lesions are classified into three subtypes according to their localizations. They can be seen either on the gingiva (Bohn's nodules), along the midline of the palate (Epstein's pearls) or on ingrowth ectodermal laminar surfaces of the oral cavity (dental lamina cysts). When noticed by the anxious parents on the gingival surfaces, they

M. N. Cizmeci $(\bowtie) \cdot$ M. K. Kanburoglu $\cdot$ S. Kara $\cdot$ M. M. Tatli Department of Pediatrics, Division of Neonatology, Fatih University Medical School, Alparslan Turkes Caddesi, No:57, P.O:06510, Emek/Ankara, Turkey

e-mail: nevzatcizmeci@gmail.com

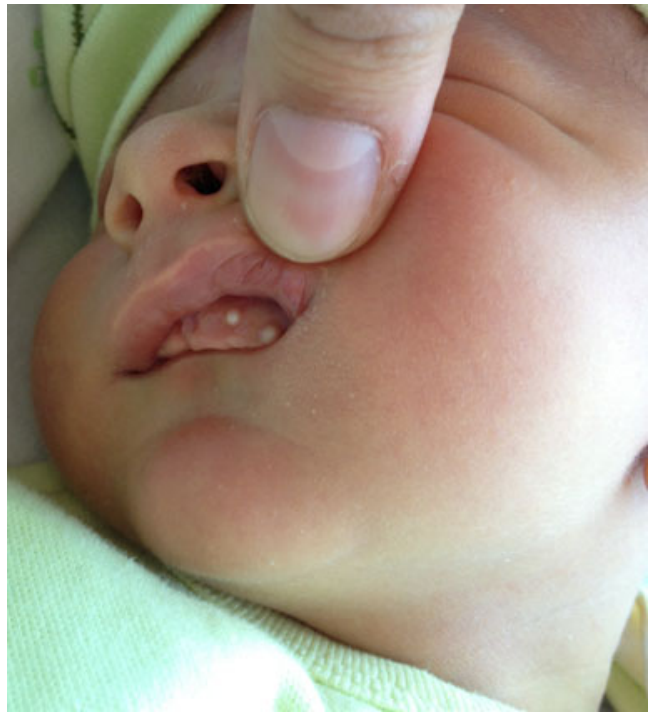

Fig. 1 Small, firm, white-colored lesions on the maxillary gingival surface consistent with Bohn's nodules

are often mistaken for natal teeth, which lead to seeking medical attention. Physicians should be able to recognize these lesions, explain its benign, self-limiting nature to the caregivers, and reassure them to avoid unnecessary medical or surgical intervention. The cysts usually disappear spontaneously between 1 and 2 weeks of birth [1,2].

\section{References}

1. Gupta N, Ramji S (2013) Bohn's nodules: an under-recognised entity. Arch Dis Child Fetal Neonatal Ed 98:464

2. Singh RK, Pandey RK, Singh K (2012) Dental lamina cysts in a newborn infant. BMJ Case Rep. doi:10.1136/bcr-2012-007061 